Polymer Journal, Vol. 39, No. 7, pp. 670-674 (2007)

(C) 2007 The Society of Polymer Science, Japan

\title{
Formation of $\beta$-Phase Crystalline Structure of PVDF Nanofiber by Electrospray Deposition: Additive Effect of Ionic Fluorinated Surfactant
}

\author{
Muhamad Nasir, ${ }^{1}$ Hidetoshi Matsumoto, ${ }^{1}$ Mie Minagawa, ${ }^{1}$ \\ Akihiko TANIOKA, ${ }^{1, \dagger}$ Tetsuya DANNO, ${ }^{2}$ and Hideo HORIBE ${ }^{3}$ \\ ${ }^{1}$ Department of Organic and Polymeric Materials, and International Research Center of Macromolecular Science, \\ Tokyo Institute of Technology, Mail Box S8-27, 2-12-1 Ookayama, Meguro-ku, Tokyo 152-8552, Japan \\ ${ }^{2}$ Department of Lifestyle Design, Kochi Women's University, 5-15 Eikokuji-cho, Kochi City 783-8015, Japan \\ ${ }^{3}$ Department of Materials Science and Engineering, Kochi National College of Technology, Nangoku City 783-8508, Japan
}

(Received February 7, 2007; Accepted March 20, 2007; Published May 9, 2007)

\begin{abstract}
Poly(vinylidene fluoride) (PVDF) nanofibers were prepared by electrospray deposition (ESD). In the present work, the additive effect of ionic fluorinated surfactants—anionic and cationic surfactants —on the diameter, morphology, and crystalline structure of PVDF nanofiber was investigated. The addition of ionic fluorinated surfactants is useful for the formation of bead-free homogeneous fiber. At a higher concentration of the ionic surfactants, thicker fiber was formed. In addition, the Fourier transform infrared spectroscopy and the wide angle X-ray diffraction measurements showed that the addition of both ionic fluorinated surfactants causes a complete change in conformation from the initial $\alpha$-phase of to the $\beta$-phase of PVDF during ESD. A possible mechanism based on the interaction between the polymer and surfactant molecules during ESD is discussed. [doi:10.1295/polymj.PJ2006233]

KEY WORDS Poly(vinylidene fluoride) / Crystalline Structure / Nanofiber / Electrospray Deposition / Ionic Surfactant /
\end{abstract}

Recently, nanofibers and nanofiber mats with high specific surface area have attracted much attention for the applications such as filter media, ${ }^{1}$ protective clothing, ${ }^{2}$ aerospace materials, ${ }^{3}$ electronic devices, ${ }^{4}$ tissue engineering, ${ }^{5,6}$ sensors, ${ }^{7}$ and biomedical uses. ${ }^{8,9}$ Particularly, the slip flow effect on the surface of nanofiber is potentially useful for high-efficiency air filters. ${ }^{10-13}$

Poly(vinylidene fluoride) (PVDF) is widely used for industrial applications because of its excellent chemical stability, mechanical strength, and ferroelectricity. PVDF has several crystalline structures: $\alpha, \beta$, and $\gamma$-phases, based on the chain conformation as trans or gauche linkages. ${ }^{14-23}$ The $\alpha$-phase is the most energetic stable states and the $\beta$-phase has useful piezoelectric and pyroelectric properties. ${ }^{14-16}$ Many researchers have studied the formation of the $\beta$-phase structure of PVDF by a range of polymer processes: poling under a high electric field, ${ }^{17}$ annealing, ${ }^{18,19}$ crystallization under high pressure, ${ }^{20}$ polymer blending, ${ }^{21}$ stretching ${ }^{22}$ or using additives. ${ }^{23}$ However, it is difficult to obtain the $\beta$-phase crystalline structure of PVDF by conventional processes. Electrospray deposition (ESD) is an electric field induced spray processing and a versatile method for the preparation of nano-microscaled fiber. ${ }^{24}$ Our previous study revealed that the addition of nonionic hydrofluorocarbon remarkably enhanced the formation of the $\beta$ - phase structure of the PVDF nanofiber during the ESD process. ${ }^{23}$ In the ESD process, ionic additives are also effective for controlling the fiber diameter. ${ }^{25}$ The aim of the present work is to investigate the effect of ionic fluorinated surfactant on the diameter, morphology, and crystalline structure of PVDF nanofiber by ESD.

\section{EXPERIMENTAL}

\section{Materials}

Poly(vinylidene fluoride) (PVDF, $M_{\mathrm{w}}=141,000$, $\left.M_{\mathrm{n}}=64,000, \mathrm{KF} 1100\right)$ and $N, N$-dimethylacetamide (DMAc) were obtained from Kureha, Japan and Wako, Japan, respectively. Anionic fluorinated surfactant having a carboxylic acid group (Surflon ${ }^{\circledR}$ S-113) and a cationic fluorinated surfactant having a trimethyl ammonium group (Surflon ${ }^{\circledR}$ S-121) were from Seimi Chemical, Japan. Before use, PVDF was dissolved in $N, N$-dimethylformamide at $60^{\circ} \mathrm{C}$ and then precipitated in methanol. Thereafter, PVDF was washed with methanol and then vacuum-dried for $24 \mathrm{~h}$. Other reagents were used without further purification. A spray solution was prepared as follows: Purified PVDF and ionic fluorinated surfactant were dissolved in DMAc and then stirred at $60^{\circ} \mathrm{C}$ for several hours. Thereafter, the solution was cooled to a room temperature.

${ }^{\dagger}$ To whom correspondence should be addressed (Tel: +81-3-5734-2426, Fax: +81-3-5734-2876, E-mail: tanioka.a.aa@m.titech.ac.jp). 


\section{Electrospray Deposition (ESD)}

The ESD setup is the same as that previously mentioned. ${ }^{23}$ The conditions of ESD were as follows: the distance between the nozzle tip and the grounded collector (Al sheet) was $12 \mathrm{~cm}$, the applied voltage was $15 \mathrm{kV}$, and the feeding rate of spray solution was $2 \mu \mathrm{L} / \mathrm{min}$.

\section{Characterization of Nanofiber}

The morphology of the PVDF nanofiber made by ESD was observed using a scanning electron microscope (SM-200, Topcon, Japan) operated at $10 \mathrm{kV}$. All samples were sputter-coated with Au. The average fiber diameter was analyzed from the SEM image using Adobe Photoshop 7.0 Software (Adobe, USA). The crystallinity of the PVDF nanofiber was measured by a differential scanning calorimeter (DSC 6100, Seiko Instruments, Japan). The crystalline structure of the PVDF nanofiber was analyzed by a Fourier transform infrared spectrometer (FT-IR-410, Jasco, Japan) and an X-ray diffraction meter ( $X^{\prime}$ Pert Pro, Phillips, Netherlands).

\section{RESULT AND DISCUSSION}

\section{Additive Effect of Ionic Surfactant on Morphologies}

The properties of the spray solution are summarized in Table I. The viscosities of the spray solution with anionic fluorinated surfactant were around $1100 \mathrm{mPas}$. The viscosity of the solution with the cationic fluorinated surfactant slightly increased with an increase in the surfactant concentration but was in the range of $1100-1280 \mathrm{mPa}$. The surface tension of all spray solutions shows a similar value, 34-37 $\mathrm{mN} / \mathrm{m}$.

Figure 1 shows the morphologies of PVDF nanofiber with and without the ionic surfactant as an additive. Without the ionic surfactant, there are beads on the fiber string (Figure 1a). But by adding small amount of the ionic fluorinated surfactant, bead-free

Table I. Properties of PVDF solution for ESD

\begin{tabular}{clcc}
\hline $\begin{array}{c}\text { Concentration of surfactant } \\
\text { (wt \%) }\end{array}$ & $\begin{array}{c}\text { Viscosity } \\
(\mathrm{mPa})\end{array}$ & $\begin{array}{c}\text { Surface tension } \\
(\mathrm{mN} / \mathrm{m})\end{array}$ \\
\hline \multirow{3}{*}{ Anionic } & 0 & 1090 & 35.83 \\
surfactant & 0.2 & 1047 & 36.13 \\
& 0.5 & 1060 & 36.23 \\
& 1 & 1140 & 35.35 \\
Cationic & 2 & 1195 & 37.15 \\
surfactant & 3 & 1105 & 35.25 \\
& 0.2 & 1100 & 37.35 \\
& 0.5 & 1180 & 38.30 \\
& 1 & 1210 & 36.85 \\
& 2 & 1220 & 34.40 \\
& 3 & 1280 & 34.0 \\
\hline
\end{tabular}

nanofiber was obtained. In comparison, in our previous work, ${ }^{23}$ bead-free nanofiber was obtained at a higher PVDF concentration $(26 \mathrm{wt} \%)$. The result revealed that the addition of the ionic fluorinated surfactant is useful for the formation of bead-free homogeneous nanofiber. Park et al. have pointed out that the addition of electrolyte to the polymer solution increased the charge density in ejected jet and thus stronger forces were imposed to the jet due to the self-repulsion of the excess charges under the electric field, resulting in substantially straighter shape of as-deposited fiber. ${ }^{26}$

Figure 2 shows the effect of ionic fluorinated surfactant concentration on fiber diameter. In the range of ionic fluorinated surfactant concentration, 0 to 0.5 wt $\%$, the fiber diameter decreased with an increase in the ionic fluorinated surfactant concentration. Thereafter, above $0.5 \mathrm{wt} \%$, the diameter of the fiber gradually increased. To examine the formation of the morphologies by ESD, we measured the volumetric charge density of the spray jet during ESD (current divided by flow rate of polymer solution). Figure 3 show the electrical properties of spray jet during ESD. The volumetric charge density increased with an increase in the ionic fluorinated surfactant concentration. The contribution of anionic and cationic fluorinated surfactants to the volumetric charge density is almost same. Rutledge et al. have pointed out that the fiber diameter correlates with the charge density. Therefore, increase in PVDF fiber diameter can be explained by increased in the concentration of ionic fluorinated surfactant concentration. When the concentration of ionic fluorinated surfactant is too high, the electrospray phenomenon can not occur easi$1 y .{ }^{27-30}$

\section{Additive Effect of Ionic Surfactant on Crystalline Structure}

The crystallinity of the nanofibers determined by DSC measurement is shown in Table II. Crystallinity of the fiber is around 50-60\%. Addition of ionic fluorinated surfactant to the polymer solution influences the physical properties of the PVDF nanofiber. Interestingly, Table II shows that the crystalinity of the fiber with cationic fluorinated surfactant is lower than that of other fibers. This result indicated that the interaction between the cationic fluorinated surfactant and PVDF influenced the decreased in crystalinity of PVDF.

The additive effect of the ionic fluorinated surfactants on the formation of crystalline structure of the PVDF nanofiber was analyzed by FT-IR and WAXD. The FT-IR analysis shows that the vibration peaks of $\alpha$-phase crystal at $766 \mathrm{~cm}^{-1}$ disappeared for both PVDF with the ionic fluorinated surfactants 

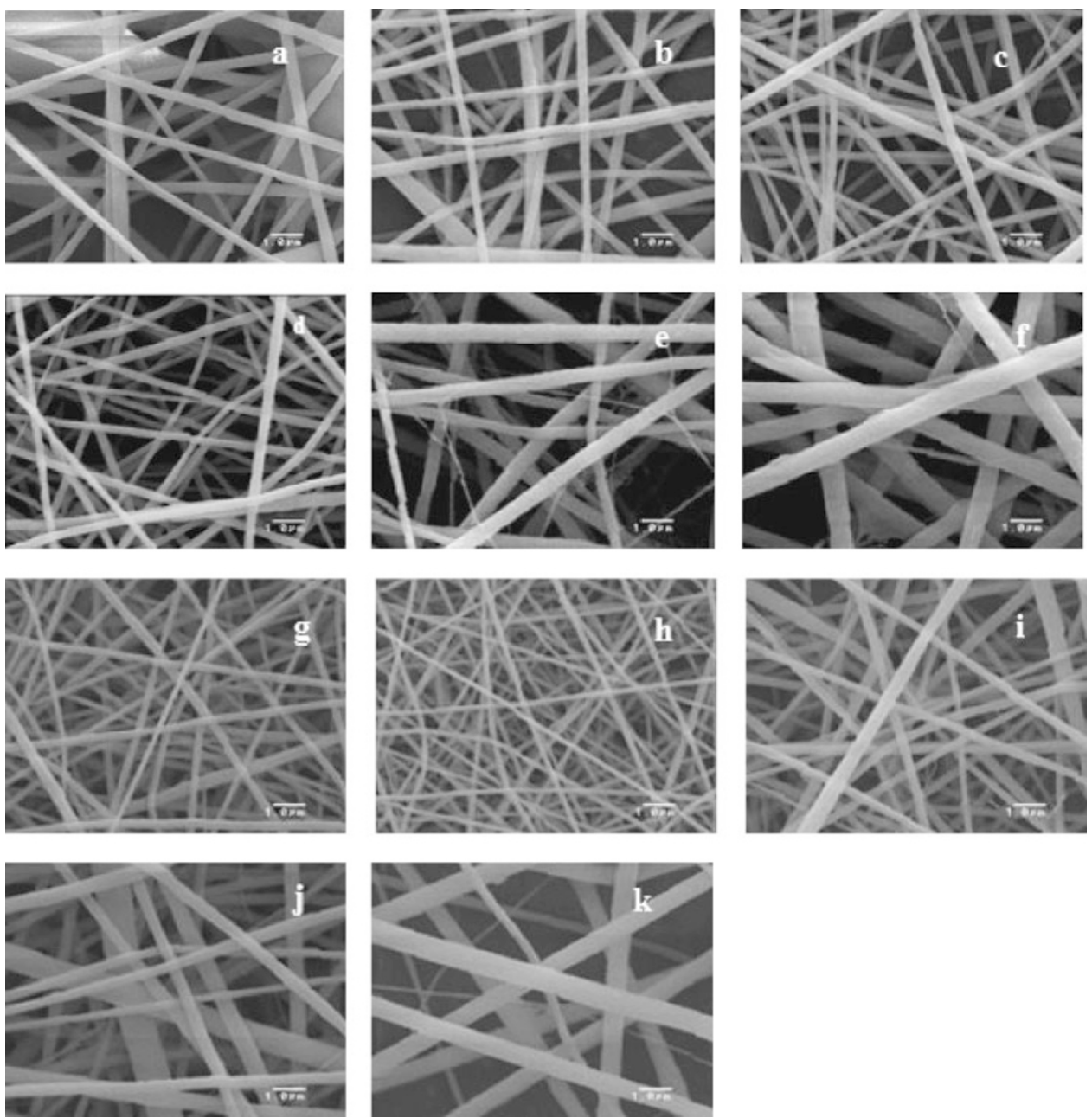

Figure 1. Surface SEM image of nanofiber by ESD from $20 \mathrm{wt} \%$ PVDF with various concentrations of ionic surfactant. (a) without the surfactant; with (b) $0.2 \mathrm{wt} \%$, (c) $0.5 \mathrm{wt} \%$, (d) $1 \mathrm{wt} \%$, (e) $2 \mathrm{wt} \%$, and (f) $3 \mathrm{wt} \%$ cationic surfactant; and with (g) $0.2 \mathrm{wt} \%$, (h) $0.5 \mathrm{wt} \%$, (i) $1 \mathrm{wt} \%$, (j) $2 \mathrm{wt} \%$ and (k) $3 \mathrm{wt} \%$ anionic surfactant.

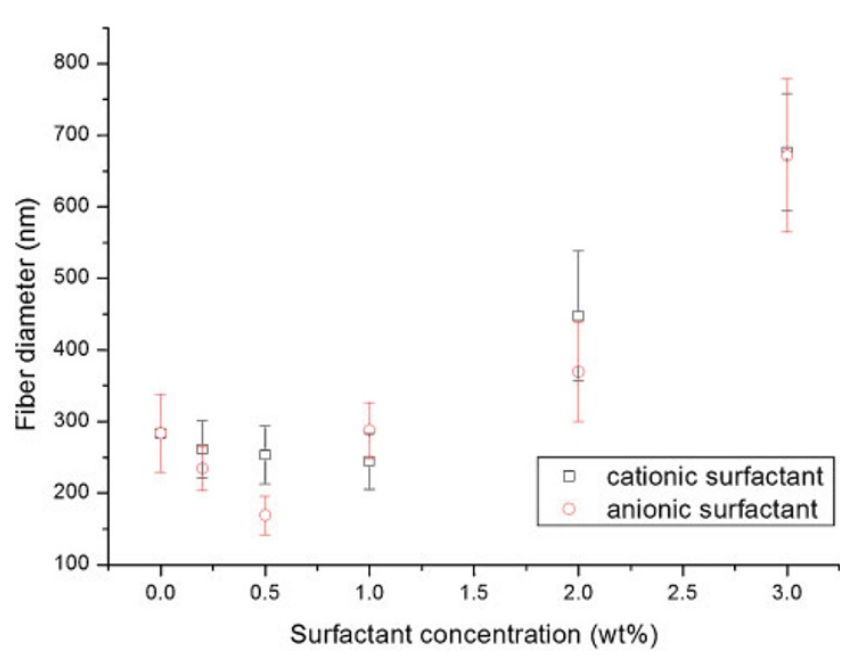

Figure 2. Effect of concentration of the ionic fluorinated surfactant on fiber diameter.

(Figure 4). The ratio of the $\beta$-phase to $\alpha$-phase, which is calculated from the absorbance of the respective vibration band peaks of FT-IR spectra ( $\beta$-phase: $840 \mathrm{~cm}^{-1}$ and $\alpha$-phase: $\left.766 \mathrm{~cm}^{-1}\right),{ }^{23}$ are shown in

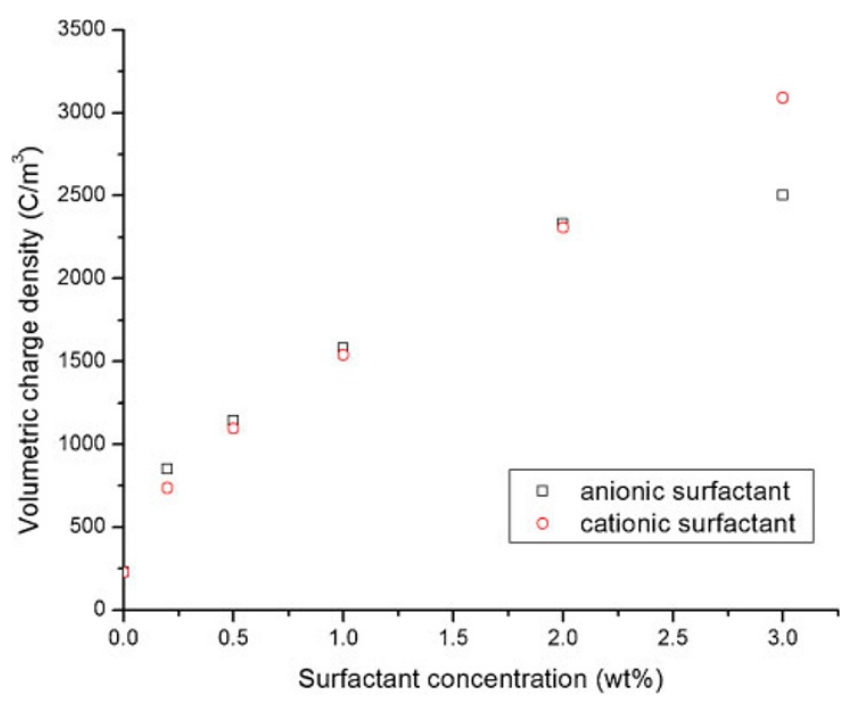

Figure 3. Volumetric charge density of spray jet as a function of surfactant concentration.

Table II. The WAXD diagram also shows that 2 theta peak at 20.3, corresponding to $\beta$-phase crystal, ${ }^{23}$ was observed for PVDF with both ionic fluorinated surfac- 
Table II. Total crystallinity and ratio of $\beta$-phase to $\alpha$-phase of the PVDF nanofibers by ESD

\begin{tabular}{lcc}
\hline \multicolumn{1}{c}{ Sample } & $\begin{array}{c}\text { Total } \\
\text { crystallinity }(\%)^{*}\end{array}$ & $\beta / \alpha^{* *}$ \\
\hline as-received PVDF & 77.0 & 2.12 \\
as-deposited PVDF & 61.9 & 3.24 \\
$\begin{array}{l}\text { as-deposited PVDF } \\
\text { with } 1 \text { wt } \%\end{array}$ & 52.7 & $\begin{array}{c}\text { Complete } \\
\text { cationic surfactant }\end{array}$ \\
$\begin{array}{l}\text { as-deposited PVDF } \\
\text { with 1 wt } \%\end{array}$ & & $\begin{array}{c}\text { Complete } \\
\text { anionic surfactant }\end{array}$ \\
\hline
\end{tabular}

*Determined by DSC measurements. ${ }^{* *}$ Calculated from the absorbance of the vibration band peaks of FT-IR spectra at $840 \mathrm{~cm}^{-1}$ and $766 \mathrm{~cm}^{-1} .^{23}$

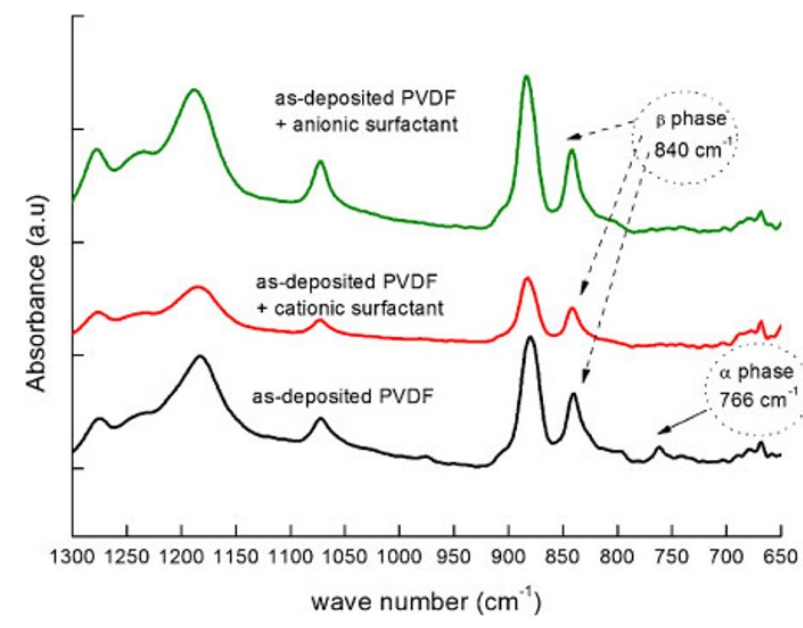

Figure 4. FT-IR spectra of PVDF nanofiber by ESD with and without ionic surfactant. The concentration of the anionic surfactants is $0.5 \mathrm{wt} \%$, and the concentration of cationic surfactant is $1 \mathrm{wt} \%$ respectively.

tants; and that the peaks at $17,18.6$, and 26 to $32,{ }^{23}$ corresponding to $\alpha$-phase crystal, was not observed for PVDF with both ionic fluorinated surfactants (Figure $5 b$ ). For comparison, the crystalline structure of the as-deposited PVDF with water and isopropanol (IPA) was analyzed by WAXD, because the ionic surfactant used here contains the mixture of water and IPA as a solvent. The WAXD diagram demonstrated that PVDF with the solvents contained both $\alpha$ - and $\beta$-phase crystals (Figure 5a). These results indicate that the addition of ionic fluorinated surfactants is effective for the formation of complete $\beta$-phase crystal of PVDF during ESD.

We proposed the mechanism on rearrangement of the PVDF crystalline structure in the presence of the ionic fluorinated surfactants by ESD process (Figure 6). This mechanism is mainly induced by the interaction between the positive charge in the ionic surfactant and fluorine atom in PVDF molecule
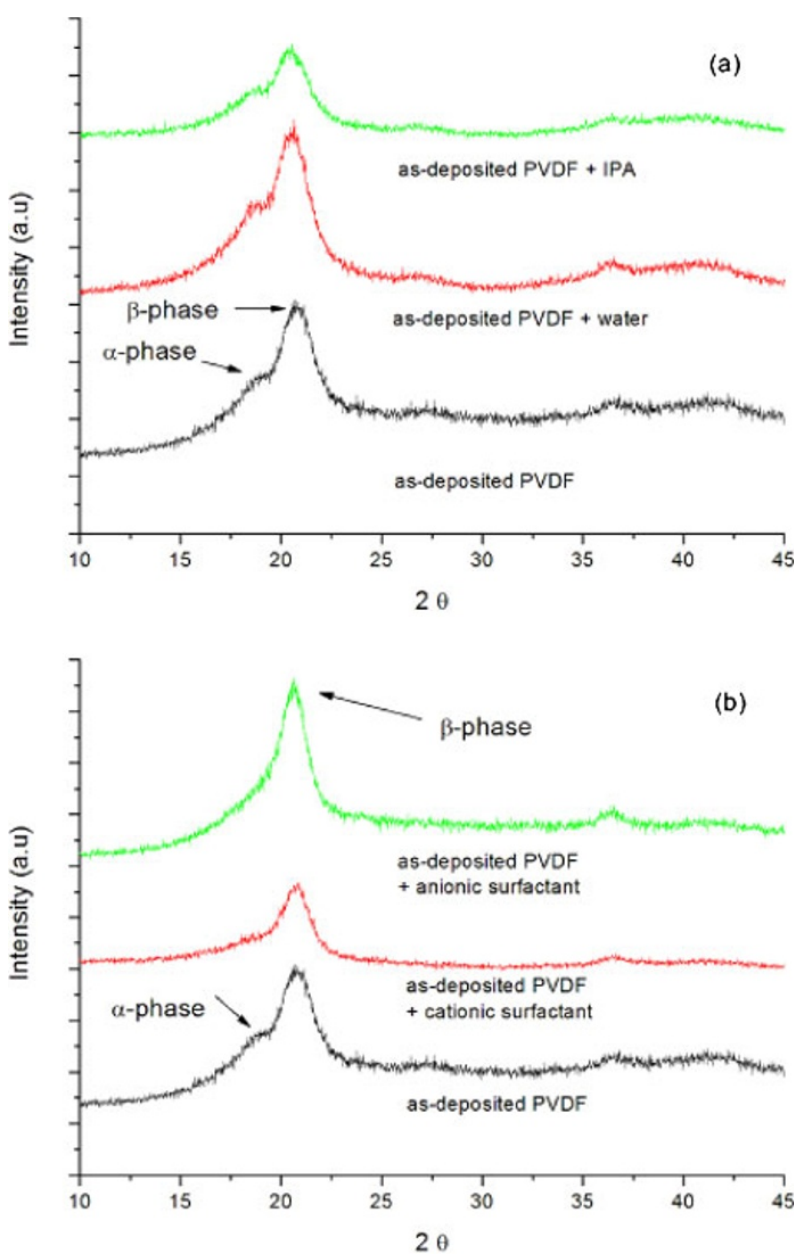

Figure 5. WAXD diagram of PVDF nanofiber by ESD. a) asdeposited PVDF with water and isopropanol as additives (the water concentration is $1 \mathrm{wt} \%$ and isopropanol concentration is $1 \mathrm{wt} \%$ ). b) as-deposited PVDF with and without ionic surfactant (the concentration of anionic surfactants is $1 \mathrm{wt} \%$, and the concentration of the cationic surfactant is $1 \mathrm{wt} \%$ respectively).

(or negative charge in the ionic surfactant and hydrogen atom in PVDF molecule) and high electric filed. Our previous paper, however, showed that non-ionic fluorinated additive enhanced the formation of $\beta$ phase crystalline structure of PVDF but the formation of complete $\beta$-phase structure was not accomplished. This result supports that the effect of ionic groups of fluorinated surfactant is substantial for the formation complete $\beta$-phase crystalline structure of PVDF during ESD.

\section{CONCLUSION}

In the present study, the additive effect of ionic fluorinated surfactants on diameter, morphology and crystalline structure of PVDF nanofiber by ESD was investigated. The addition of ionic fluorinated surfactants is useful for the formation of bead-free homogeneous fibers. With greater concentration of the ionic 

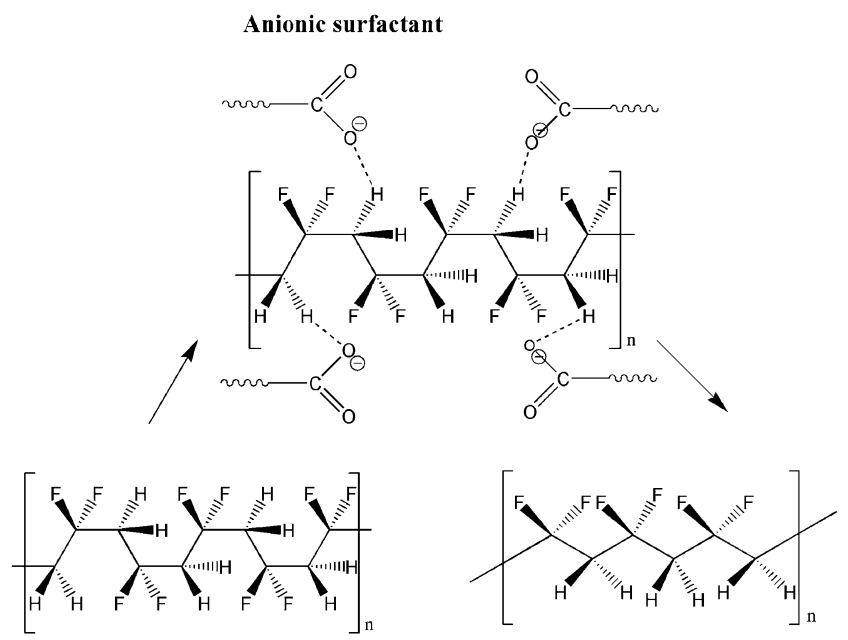

$\alpha$-phase

$\beta$-phase

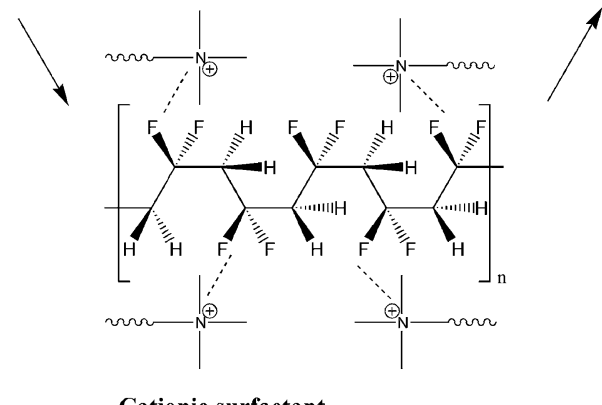

Cationic surfactant

Figure 6. Mechanism of the $\alpha$ to $\beta$-phase crystalline transformation.

fluorinated surfactants, a thicker fiber was formed. The FT-IR and the WAXD measurements showed that the initial $\alpha$-phase of as-received PVDF was completely converted to $\beta$-phase PVDF during ESD from PVDF solution with the anionic or cationic fluorinated surfactant. This indicates that the interaction between the hydrogen atom or fluorine atom of PVDF and the charge group of surfactant plays an important role in the formation of the $\beta$-phase structure during ESD. These results also provide fundamental information about the formation of $\beta$-phase PVDF. The $\beta$-phase PVDF is a promising material for high efficiency filter media (e.g., air filter for charged molecules) sensors, and actuators.

\section{REFERENCES}

1. K. Yoon, K. Kim, X. Wang, D. Fang, B. S. Hsiao, and B. Chu, Polymer, 47, 2434 (2006).

2. C. Huang, S. Chen 1, D. H. Reneker, C. Lai, and H. Hou, Adv. Mater., 18, 668 (2006).

3. G. Zhang, W. Kataphinan, R. Teye-Mensah, P. Katta, L. Khatri, E. A. Evans, G. G. Chase, R. D. Ramsier, and
D. H. Reneker, Mater. Sci. Eng., B, 116, 353 (2005).

4. A. N. Aleshin, Adv. Mater., 18, 17 (2006).

5. A. Greiner, J. H. Wendorff, A. L. Yarin, and E. Zussman, Appl. Microbiol. Biotechnol., 71, 387 (2006).

6. Q. P. Pham, U. Sharma, and A. G. Mikos, Tissue Eng., 12, 1197 (2006).

7. J. Huang, S. Virji, B. H. Weiller, and R. B. Kaner, J. Am. Chem. Soc., 125, 314 (2003).

8. J. B. Chiu, Y. K. Luu, D. Fang, B. S. Hsiao, B. Chu, and M. Hadjiargyrou, J. Biomed. Nanotechnol., 1, 115 (2006).

9. S. N. Lakshmi, S. Bhattacharyya, J. D. Bender, Y. E. Greish, P. W. Brown, H. R. Allcock, and C. T. Laurencin, Biomacromolecules, 5, 2212 (2004).

10. P. Gibson, H. Schreuder-Gibson, and D. Rivin, Colloids Surf. A, 187-188, 469 (2001).

11. V. A. Kirsh, Colloid J., 62, 714 (2000).

12. M. N. Lebedev, I. B. Stechkina, and A. L. Chernyakov, Colloid J., 62, 731 (2000).

13. S. Yang and W. M. L. Grace, J. Aerosol Sci., 36, 419 (2005).

14. N. C. Banik, F. P. Boyle, T. J. Sluckin, P. L. Taylor, S. K. Tripathy, and A. J. Hopfinger, J. Chem. Phys., 72, 3191 (1980).

15. S. B. Lang and S. Muensit, Appl. Phys. A: Mater. Sci. Process., 85, 125 (2006).

16. R. Hasegawa, Y. Takahashi, Y. Chatani, and H. Tadokoro, Polym. J., 3, 600 (1969).

17. Y. Ye, Y. Jiang, Z. Wu, and H. Zeng, Integrated Ferroelectrics, 80, 245 (2006).

18. M. Benz and W. B. Euler, J. Appl. Polym. Sci., 89, 1093 (2003).

19. M. Neidhofer, F. Beaume, L. Ibos, A. Bernes, and C. Lacabanne, Polymer, 45, 1679 (2004).

20. T. Hattori, M. Kanaoka, and H. Ohigashi, J. Appl. Phys., 79, 2016 (1996).

21. R. Gregorio Jr. and N. C. P. S. Nociti, J. Phys. D: Appl. Phys., 28, 432 (1995).

22. A. Salimi and A. A. Yousefi, Polym. Test., 22, 699 (2003).

23. M. Nasir, H. Matsumoto, T. Danno, M. Minagawa, T. Irisawa, M. Shioya, and A. Tanioka, J. Polym. Sci., Part B: Polym. Phys., 44, 779 (2006).

24. K. Morota, H. Matsumoto, T. Mizukoshi, Y. Konosu, M. Minagawa, A. Tanioka, Y. Yamagata, and K. Inoue, $J$. Colloid Interface Sci., 279, 484 (2004).

25. H. Dong, V. Nyame, A. Macdiarmid, and W. E. Jones Jr., J. Polym. Sci., Part B: Polym. Phys., 42, 3393 (2004).

26. W. K. Son, J. H. Youk, T. S. Lee, and W. H. Park, Polymer, 45, 2959 (2004).

27. Y. M. Shin, M. M. Hohman, M. P. Brenner, and G. C. Rutledge, Polymer, 42, 9955 (2001).

28. M. H. Hohman, Mi. Shin, G. Rutledge, and M. P. Brenner, Physic of Fluids, 13, 2221 (2001).

29. M. H. Hohman, M. G. Rutledge, and M. P. Brenner, Phys. Fluids, 13, 2202 (2001).

30. S. V. Friedrick, J. H. Yu, M. P. Brener, and G. Rutledge, Phys. Rev. Lett., 90, 144502 (2003). 